\title{
ROLE OF DIGITAL SUBTRACTION ANGIOGRAPHY IN DETECTION OF INTRACRANIAL ANEURYSMS COMPARED WITH COMPUTED TOMOGRAPHIC ANGIOGRAPHY
}

\author{
S Maniharan ${ }^{1}$, A D P Athukorala ${ }^{1}$, D L N Pullaperuma ${ }^{1}$, S Pirasath ${ }^{2}$, I N Lekamge ${ }^{1}$. \\ ${ }^{1}$ Angiography Unit, Neuro-trauma Centre, National Hospital of Sri Lanka, \\ ${ }^{2}$ Medical Unit, Colombo South Teaching Hospital, Kalubowila, Sri Lanka.
}

Keywords: Digital subtraction angiogram, intracranial aneurysm, subarachnoid hemorrhage, computed tomographic angiogram.

Corresponding Author: Sathiyaseelan Maniharan

Copyright: Sathiyaseelan Maniharan

iD https://orcid.org/0000-0003-4890-5901

\begin{abstract}
Objective To evaluate the role of digital subtraction angiography (DSA) in the detection of intracranial aneurysms among patients with spontaneous subarachnoid hemorrhage (SAH) compared with computed tomographic angiography (CTA) in a single center, Sri Lanka.
\end{abstract}

Methods A total of 123 patients clinically and CT proven SAH were evaluated with CT angiography and DSA with a median interval of 3 days. The sensitivity, specificity and accuracy of CT angiography in detecting aneurysms were analyzed compared to DSA on a perpatient, per-size, per-site and per morphological basis. All data were analyzed using SPSS analytical package (version 18). Ethical approval for the study was from the institutional ethical review board.

Results Among 123 patients with clinically and CT proven SAH, 51 (41.5\%) patients showed aneurysms on CT angiography. 72 were negative for aneurysms in CTA. In 13 out of 72 (18\%) CTA negative patients subsequent DSA demonstrated aneurysms. Number of CTA negative but DSA positive aneurysm were 15 as two of the patients had two aneurysms each.

Four CTA detected aneurysms could not be appreciated in the subsequent DSAs. Aneurysms (47) detected by both CT angiography and DSA were more than $6 \mathrm{~mm}$ in size $(56.7 \%)$, saccular type $(96.5 \%)$ and were located in the anterior circulation system $(92.4 \%)$.

Most CTA negative aneurysms detected by DSA were less than $6 \mathrm{~mm}$ in size (80\%), saccular type $(60 \%)$ and were located in anterior $(53.8 \%)$ and posterior $(46.7 \%)$ circulation system.

The sensitivity, specificity, positive predictive value and negative predictive value of CT angiography compared to DSA per patient basis were $78.3 \%, 93.7 \%, 92.2 \%$ and $81.9 \%$ respectively. 
CT angiography has a low sensitivity to detect aneurysms less than $6 \mathrm{~mm}$ size $(65.7 \% \%)$, in posterior circulation $(36.4 \%)$ and other morphological types $(0 \%)$ compared to aneurysms more than $6 \mathrm{~mm}$ size $(90.9 \%)$, in anterior circulation (85.9\%) and saccular type (85.5\%).

Conclusion Digital subtraction angiography (DSA) has a significant role in detecting intracranial aneurysms which are less than $6 \mathrm{~mm}$ in size, are located in posterior circulation system and of non-saccular morphological type.

\section{Introduction}

Subarachnoid haemorrhage is associated with high mortality and morbidity ${ }^{1}$ and is a health burden globally with an incidence rate of 9 per 100000 populations per year ${ }^{2}$. Re-bleeding is common and can be catastrophic. Delayed cerebral ischemia is a common complication usually occurring in around $33 \%$ of patients between 4 to 14 days from the onset of $\mathrm{SAH}^{2}$. Early recognition and prompt treatment of underlying etiology reduces the morbidity and mortality and leads to better outcomes among victims. The current accepted practice in patients with spontaneous SAH is either CT angiography and/or Digital Subtraction Angiography (DSA) with a view to detect the underlying etiology of bleeding. DSA is the gold standard investigation $^{3}$ to detect intracranial aneurysms, which is an invasive and time-consuming imaging modality and needs to be performed by experienced operators.

There are several international studies that were carried out to compare CT angiography and DSA modalities ${ }^{4,5}$. However, there are no relevant local data available to inform local clinical practice. The value of DSA in CTA negative SAH is still not fully established worldwide while different expert opinions contradict each other. Here we have evaluated the diagnostic accuracy of digital subtraction angiography over CTA in the detection of intracranial aneurysms in patients with spontaneous SAH among 123 patients, with DSA serving as the reference standards in a cohort at a single center in Sri Lanka.

\section{Materials and Methods}

\section{Patient Population}

123 patients (54 males, 69 females) with clinically proven spontaneous SAH who underwent non-contrast CT brain were included in this retrospective study.

All patients with non-contrast CT proven SAH referred to Angiography section, Neuro-trauma center, National Hospital of Sri Lanka for DSA study from $1^{\text {st }}$ February 2017 to $31^{\text {st }}$ January 2018 were included in this study.

The patients with history of head trauma, known intracranial vascular abnormalities and DSA done after 14 days from the onset of symptoms were excluded from the study.

The patient details were taken from the institutional based records. In patients referred with spontaneous SAH, available printed NCCT brain images were reviewed and confirmed to have $\mathrm{SAH}$ by experts in radiology. The CTA findings were obtained from the reports issued by experts in radiology and images assessed by the interventional radiology team. DSA studies 
were carried out and were reported by a Consultant Interventional Radiologist and a Senior Registrar in Interventional Radiology.

\section{CT angiography and DSA imaging studies and analysis}

\section{CT angiography}

CTA was done using a 16-slice configuration CT system (Somatom Emotion; Siemens Healthcare, Germany). Low osmolar water soluble nonionic iodinated contrast medium was injected at a rate of $4.0 \mathrm{~mL} / \mathrm{sec}$ into the antecubital vein via a 22 -gauge cannula, followed by $20 \mathrm{~mL}$ of saline chase. Imaging started 6 seconds after the attenuation reached the predefined $100 \mathrm{HU}$ threshold. Non contrast and contrast CT data were transferred to a Syngoplaza workstation, Siemens Healthcare and image reconstruction was done after removal of bone voxels. Maximum intensity projection, volume rendering, and multiplanar reformation were reconstructed in all cases. CTA images and reports were assessed by a Consultant Interventional Radiologist before proceeding to DSA.

\section{Digital subtraction angiography}

DSA studies were performed with catheterization of femoral artery using the Seldinger technique and a biplane DSA unit with 3D rotational capabilities (Infinix-I Biplane, Toshiba, Japan) was used for imaging. Nonionic iodinated contrast medium (300 mg of iodine per milliliter Iopromide, Ultravist 300) was used for each angiogram. Angiographic catheter was used to cannulate carotid and vertebral arteries and standard anteroposterior, lateral, and oblique DSA images were taken. The 3D angiographic data were transferred to Vitrea 3D workstation; Toshiba for visualization and for reformation of images. If an aneurysm was identified, diameter of the aneurysm was measured and the location recorded. The diameter of each aneurysm was measured in millimeters to one decimal place and graded by a Consultant Interventional Radiologist.

\section{Statistical Analysis}

All data were entered in Microsoft excel and analyzed using SPSS (version 18) package. The results were expressed as mean \pm standard deviation and percentages. The sensitivity, specificity, positive and negative predictive values and accuracy of CT angiography versus DSA were calculated based on size, site, and morphological basis. The $\mathrm{P}$ value of $\leq 0.05$ was considered as significant.

\section{Ethical approval}

The ethical approval was obtained from the ethics review committee of National Hospital of Sri Lanka. 


\section{Results}

\section{Overall Accuracy of CT angiography and Digital Subtraction Angiography}

Among 123 patients with clinically and CT proven SAH, 51 (41.5\%) patients had aneurysms while $72(58.5 \%)$ patients had no detectable aneurysms at CT angiography.

Among patients with aneurysms detected by CT angiography, $47(91.2 \%)$ patients were detected to have aneurysms at DSA while 13 out of 72 patients $(18.1 \%)$ with negative CT angiography were detected to have aneurysms at DSA (Table 1).

Total number of aneurysms detected by DSA was 68 in 60 patients. DSA detected 15 aneurysms in 13 CTA negative patients. DSA confirmed 53 aneurysms in 47 CTA positive patients, while aneurysms were not detected in 4 patients who were reported to be having aneurysms on CTA. (Table 1).

CT angiographic and Digital Subtraction Angiographic accuracy according to aneurysm size

The size of aneurysms detected by CT angiography and DSA are shown in Table 2 and Table 3 . The majority of aneurysms detected by CT angiography was more than $6 \mathrm{~mm}$ in size (Nos$30,56.7 \%$ ). The majority of aneurysms detected by DSA among CT negative angiography were less than $6 \mathrm{~mm}$ in size (Nos-12, $80 \%$ ).

\section{CT angiographic and Digital Subtraction Angiographic accuracy according to aneurysm location}

Most aneurysms detected by CT angiography were located in the anterior circulation system (Nos-53, 92.9\%).

The percentage of aneurysms not diagnosed by CTA is $14 \%$ for anterior circulation aneurysms, whereas it is $63 \%$ for posterior circulation

The locations of aneurysms detected by CT angiography and DSA were shown in Table 2.

\section{CT angiographic and Digital Subtraction Angiographic accuracy according to aneurysm} morphology

All aneurysms detected by CT angiography were of saccular type (100\%). Most aneurysms detected by DSA among CT negative angiography were also of saccular type (60\%). The morphological types of aneurysms detected by CT angiography and DSA were shown in Table 2.

\section{Statistical analysis}

The sensitivity, specificity, positive predictive value (PPV), negative predictive value (NPV), positive like hood ratio and negative like hood ratio of CT angiography compared to DSA per patient basis were $78.3 \%, 93.7 \%, 92.2 \%, 81.9 \%, 12.4 \%$ and $0.23 \%$ respectively (Table 1 ). The sensitivity, specificity, PPV and NPV of CT angiography compared to DSA per aneurysmal 
size, location and morphology basis were $79.9 \%, 93.7 \%, 92.9 \%$ and $79.7 \%$ respectively (Table 1).

The sensitivity, specificity, PPV and NPV of CT angiography compared to DSA per aneurysmal size were $90.9 \%, 96.7 \%, 93.7 \%$ and $81.9 \%$ respectively (Table 1 ). The sensitivity, specificity, PPV and NPV of CT angiography compared to DSA per aneurysmal location basis were $36.4 \%, 100 \%, 100 \%$ and $89.4 \%$ respectively (Table 1). The sensitivity, specificity, PPV and NPV of CT angiography compared to DSA per aneurysmal morphology basis were $0 \%$, $96.7 \%, 0 \%$ and $90.8 \%$ respectively (Table 1 ).

CT angiography has low sensitivity to detect less than $6 \mathrm{~mm}$ size $(65.7 \% \%)$, posterior circulation (36.4\%) and non-saccular types (0\%) aneurysms compared to more than $6 \mathrm{~mm}$ size $(90.9 \%)$, anterior circulation $(85.9 \%)$ and saccular type (85.5\%) aneurysms (Table 1).

Table 1: Role of Digital subtraction angiography and CT angiography to detect intracranial aneurysms per patient, size, location and morphological basis among patients with subarachnoid hemorrhage.

\begin{tabular}{|c|c|c|c|c|c|c|c|c|c|}
\hline Variables & & & & & & Statistical & analysis & & \\
\hline & TP & $T N$ & FP & $F N$ & Sensitivity & Specificity & PPV & NPV & Accuracy \\
\hline Per patient basis & 47 & 59 & 4 & 13 & $78.3(47 / 60)$ & $93.7(59 / 63)$ & $92.2(47 / 51)$ & $81.9(59 / 72)$ & $86.2(106 / 123)$ \\
\hline Per aneurysms basis & 53 & 59 & 4 & 15 & $77.9(53 / 68)$ & $93.7(59 / 63)$ & $92.9(53 / 57)$ & $79.7(59 / 74)$ & $85.5(112 / 131)$ \\
\hline \multicolumn{10}{|c|}{ Per size of aneurysms basis } \\
\hline e6mm & 23 & 59 & 2 & 12 & $65.7(23 / 35)$ & $96.7(59 / 61)$ & $92.0(23 / 25$ & $83.1(59 / 71)$ & $85.4(82 / 96)$ \\
\hline $86 \mathrm{~mm}$ & 30 & 59 & 2 & 3 & $90.9(30 / 33)$ & $96.7(59 / 61)$ & $93.7(30 / 32]$ & $81.9(59 / 72)$ & $94.7(89 / 94]$ \\
\hline \multicolumn{10}{|c|}{$\begin{array}{l}\text { Per location of aneurysms } \\
\text { basis }\end{array}$} \\
\hline Anterior circulation. & 49 & 59 & 4 & 8 & $85.9(49 / 57)$ & $93.6(59 / 63)$ & $92.5(49 / 53)$ & $88.1(59 / 67)$ & $90.0(108 / 120)$ \\
\hline $\begin{array}{l}\text { Posterior } \\
\text { circulation }\end{array}$ & 4 & 59 & 0 & 7 & $36.4[4 / 11]$ & $100(59 / 59)$ & $100(4 / 4)$ & $89.4(59 / 66)$ & $90.0(63 / 70)$ \\
\hline \multicolumn{10}{|l|}{$\begin{array}{l}\text { Per morphology } \\
\text { aneurysms basis }\end{array}$} \\
\hline Saccular aneurysms & 53 & 59 & 2 & 9 & $85 . S(53 / 62)$ & $96.7(59 / 61)$ & $96.4(53 / 55)$ & $86.8(59 / 68)$ & $91.1(112 / 123)$ \\
\hline Others & 0 & 59 & 2 & 6 & $0\{0 / 6\}$ & $96.7(59 / 61)$ & $0 \mid 0 / 2)$ & $90.8(59 / 65)$ & $88.1(59 / 67)$ \\
\hline
\end{tabular}

Note: Abbreviations: TP; True Positive, TN: True Negative, FP: False Positive, FN: False Negative, PPV: Positive Predictive Value, NPV: Negative Predictive Value. 
Table 2: Distribution of intracranial aneurysms detected by CT angiography (CTA) and Digital Subtraction angiography (DSA) per size, location and morphological basis among patients with subarachnoid hemorrhage [CTA (+) and DSA (+) ve cases -53, CTA (-) and DSA (+) ve cases $-15]$.

\begin{tabular}{|c|c|c|c|c|}
\hline $\begin{array}{l}\text { Characteristic } \\
\text { of aneurysms }\end{array}$ & $\begin{array}{l}\text { CTA(+ve) } \\
\text { [Number- }\end{array}$ & $\begin{array}{l}\text { DSA (+ve) } \\
53]\end{array}$ & $\begin{array}{l}\text { CTA (-) ve } \\
\text { [Number- }\end{array}$ & $\begin{array}{l}\text { DSA(+ve) } \\
15]\end{array}$ \\
\hline Size & Nos & $(\%)$ & Nos & $(\%)$ \\
\hline $0-3 \mathrm{~mm}$ & 6 & 11.3 & 6 & 40 \\
\hline $4-6 \mathrm{~mm}$ & 17 & 32 & 6 & 40 \\
\hline $7-10 \mathrm{~mm}$ & 24 & 45.2 & 1 & 6.7 \\
\hline $11-15 \mathrm{~mm}$ & 1 & 19 & 1 & 6.7 \\
\hline $16-20 \mathrm{~mm}$ & 3 & 5.7 & 1 & 6.7 \\
\hline$>20 \mathrm{~mm}$ & 2 & 3.8 & 0 & 0 \\
\hline
\end{tabular}

\begin{tabular}{|c|c|c|c|c|}
\hline Location & Nos & $(\%)$ & Nos & $(\%)$ \\
\hline Anterior circulation & 49 & 92.4 & 8 & 53.8 \\
\hline Anterior cerebral artery & 1 & 1.9 & 2 & 13.5 \\
\hline communicating & 12 & 22.6 & 4 & 26.7 \\
\hline Internal carotid artery & 10 & 18.8 & 0 & 0 \\
\hline
\end{tabular}




\begin{tabular}{|c|c|c|c|c|}
\hline Middle cerebral artery & 11 & 20.7 & 1 & 6.7 \\
\hline $\begin{array}{l}\text { Posterior communicating } \\
\text { artery }\end{array}$ & 15 & 28.3 & 1 & 6.7 \\
\hline Posterior circulation & 4 & 7.6 & 7 & 46.7 \\
\hline Basilar artery & 4 & 100 & 1 & 6.7 \\
\hline Posterior cerebral artery & 0 & 0 & 3 & 20 \\
\hline $\begin{array}{l}\text { Anterior inferior cerebellar } \\
\text { artery }\end{array}$ & 0 & 0 & 1 & 6.7 \\
\hline $\begin{array}{l}\text { Posterior inferior cerebellar } \\
\text { artery }\end{array}$ & 0 & 0 & 1 & 6.7 \\
\hline Vertebral artery & 0 & 0 & 1 & 6.7 \\
\hline Morphology & Nos & $(\%)$ & Nos & $(\%)$ \\
\hline Saccular aneurysm & 53 & 100 & 9 & 60 \\
\hline Fusiform aneurysm & 0 & 0 & 2 & 13.3 \\
\hline Complex aneurysm & 0 & 0 & 3 & 20 \\
\hline Pseudo aneurysm & 0 & 0 & 1 & 6.6 \\
\hline
\end{tabular}

\section{Discussion}

CT angiography is the initial imaging modality in acute SAH to detect aneurysms ${ }^{7,8}$ while digital subtraction angiography (DSA) is the gold standard imaging study. DSA may be considered in CTA negative SAH in highly suspicious cases 9,10 .

In our study, among 123 patients with clinically and CT proven SAH, 51 (41.5\%) had aneurysms at CT angiography while 13 out of 72 patients (18.1\%) with negative CT angiography had 15 aneurysms detected at DSA. The sensitivity, specificity, PPV and NPV of 
CT angiography compared to DSA per patient basis were $78.3 \%, 93.7 \%, 92.2 \%$ and $81.9 \%$ respectively in our study. Therefore, our study has proven that DSA has a significant role to detect intracranial aneurysms in comparison to CT angiography.

Several studies were carried out previously to compare the diagnostic accuracy of CT angiography with DSA in literature $(4,5)$. Some studies have concluded that negative CTA can exclude aneurysm without evaluation by DSA 11,12, 13. However, our study has depicted that CT angiography has a sensitivity of more than $90 \%$ in depicting more than $6 \mathrm{~mm}$ size of intracranial aneurysms while sensitivity is only $65 \%$ in detecting aneurysm less than $6 \mathrm{~mm}$ in size. The CTA in our study were done with a 16 slice CT scanner which may be the reason for this difference.

There were four false positive CTA results observed on the basis of DSA findings. In our study two of those four aneurysms were more than $6 \mathrm{~mm}$ in size, while two were less than $3 \mathrm{~mm}$ in size. They were saccular (Nos-2) and fusiform (Nos-2) in morphological types. Three falsepositive aneurysms were found in the middle cerebral artery, while one was arising from internal carotid artery.

CTA is a solely reliable imaging modality in many institutions globally, even though some centers considered DSA for CT angiography negative cases. The American Heart Association endorses evaluation of aneurysmal $\mathrm{SAH}^{7}$ by DSA, according to American College of Radiology Appropriateness criteria ${ }^{14}$. Majority of research experts have revealed that both imaging modalities have an acceptable accuracy for detecting a cause for $\mathrm{SAH}^{15}$ whereas clinical practice still varies among different institutions without a basis in clinical evidence.

SAH due to vertebro-basilar system aneurysm rupture at base of skull region is considered to be major challenge to be detected by CTA ${ }^{9}$. This was evident in our study as well. We found that CT angiography failed to detect 7 out of 11 aneurysms $(63.6 \%)$ in the vertebro-basilar system. However, in some studies in literature ${ }^{13,16,17}$ high quality CT angiography sufficient to accurately diagnose these vertebro-basilar aneurysms without DSA. The CTA in our study were done with 16 slice CT scanner which may be the reason for this difference as well.

Sensitivity and specificity of CTA are considered to be $100 \%$ to detect aneurysms more than 3 $\mathrm{mm}$ in size which is comparable with DSA ${ }^{18,19}$ while conventional CTA is less reliable in detecting less than $3 \mathrm{~mm}$ size aneurysms. The common aneurysms detected by CT angiography were more than $6 \mathrm{~mm}$ in size $(56.7 \%)$ and saccular type $(96.5 \%)$ which were commonly located anterior circulation system (92.4\%) in our study. The sensitivity, specificity, positive predictive value and negative predictive value CT angiography compared to DSA per aneurysmal size, location and morphology basis were $79.9 \%, 93.7 \%, 92.9 \%$ and $79.7 \%$ respectively which were similar to previous studies ${ }^{20,21}$ A previous study revealed that the overall sensitivity, specificity and accuracy of CT angiography on a per-aneurysm basis were 95.1\%, 94.1\%, and 95\%, respectively ${ }^{22}$. Furthermore, it revealed that the sensitivity, specificity, overall accuracy of aneurysms less than $3 \mathrm{~mm}$ in size were $86.1 \%, 94.1 \%$, and $88.6 \%$, respectively. More recently, another study revealed that overall sensitivity, specificity and accuracy of CT angiography per aneurysms basis were $92.5 \%, 93.3 \%$, and $92.6 \%$, respectively ${ }^{23}$. This study also showed that 
sensitivity was greater for detecting aneurysm more than $3 \mathrm{~mm}$ in size aneurysms $(96 \%)$ compared to $3 \mathrm{~mm}$ or smaller $(61 \%)$.

Multi-slice CT angiography with 64 to 360 detector rows have been shown to have a higher accuracy in detecting aneurysms less than $3 \mathrm{~mm}$ in size in recent literature ${ }^{24,25}$. DSA has a major role to rule out small aneurysms among CTA negative diffuse SAH cases ${ }^{26}$ which should be repeated within 2-6 weeks time if the initial DSA is negative ${ }^{27}$. Most of the aneurysms detected by DSA among CT negative angiography were less than $6 \mathrm{~mm}$ in size (80\%), saccular type $(60 \%)$ which were in located anterior $(53.8 \%)$ and posterior $(46.7 \%)$ circulation system in our study. CT angiography has a low sensitivity to detect less than $6 \mathrm{~mm}$ size $(65.7 \% \%)$, posterior circulation $(36.4 \%)$ and other morphological types $(0 \%)$ of aneurysms compared to more than $6 \mathrm{~mm}$ size $(90.9 \%)$, anterior circulation $(85.9 \%)$ and saccular type $(85.5 \%)$ aneurysms.

\section{Limitations:}

Retrospective study

CTA and CT brain images were assessed by the research team only using the hard copy images. (The Reporting Radiologists reports were taken in to consideration)

\section{Conclusion}

We conclude that DSA has a significant role in detecting intracranial aneurysms which are less than $6 \mathrm{~mm}$ in size, located in posterior circulation system and of different morphological types.

Among patients with acute SAH and CT negative angiography DSA should be considered as a diagnostic modality to evaluate intracranial aneurysms due to high diagnostic accuracy.

\section{Acknowledgments}

We would like to express our gratitude to technical staffs, Angiography Section, Neuro Trauma Unit and other ward staff for their untiring help provided in innumerable ways

\section{Conflicts of interest}

The authors have no conflict of interest in publishing this research paper

\section{References}

1. Lawton MT, Vates GE. Subarachnoid hemorrhage. N Engl J Med. 2017;377:257-66.

2. Macdonald RL, Schweizer TA. Spontaneous subarachnoid haemorrhage. Lancet. 2017;389:655-66

3. Franklin B, Gasco J, Uribe T, VonRitschl RH, Hauck E. Diagnostic accuracy and inter-rater reliability of 64-multislice 3D-CTA compared to intra-arterial DSA for intracranial aneurysms. J Clin Neurosci 2010;17(5):579-583. 
4. Prestigiacomo CJ, He W, Catrambone J et al.. Predicting aneurysm rupture probabilities through the application of a computed tomography angiography-derived binary logistic regression model. J Neurosurg 2009; 110(1):1-6.

5. Watanabe Y, Uotani K, Nakazawa T et al.. Dual-energy direct bone removal CT angiography for evaluation of intracranial aneurysm or stenosis: comparison with conventional digital subtraction angiography. Eur Radiol 2009; 19(4):1019-1024.

6. Romijn M, Gratama van Andel HA, van Walderveen MA et al.. Diagnostic accuracy of CT angiography with matched mask bone elimination for detection of intracranial aneurysms: comparison with digital subtraction angiography and 3D rotational angiography. AJNR Am J Neuroradiol 2008; 29(1):134-139.

7. Bederson JB, Connolly ES Jr, Batjer HH, et al. Guidelines for the management of aneurysmal subarachnoid hemorrhage: a statement for healthcare professionals from a special writing group of the Stroke Council, American Heart Association. Stroke 2009; 40: 994-25.

8. Andreas Adam, Adrian K. Dixon, Jonathan H.Gillard, Cornelia M. Schaefer. Grainger and Allison's Diagnostic Radiology. $5^{\text {th }}$ ed. Churchill livingstone.2018; 62:1482-8.

9. Manoel AL, Mansur A, Murphy A, Parrella DT, Macdonald RL, Montanera W, et al. Aneurysmal subarachnoid haemorrhage from a neuroimaging perspective. Critical Care 2014; 18:557.

10. Karamessini MT, Kagadis GC, Petsas T, Karnabatidis D, Konstantinou D, Sakellaropoulos et al. CT angiography with three-dimensional techniques for the early diagnosis of intracranial aneurysms. Comparison with intra-arterial DSA and the surgical findings. Euro J Radiol2004; 49 :212-23.

11. Marder CP, Narla V, Fink JR, Fink KRT Subarachnoid Hemorrhage: Beyond Aneurysms. AJR 2014; 202:25-37.

12. Agid R, Andersson T, Almqvist H, et al. Negative CT angiography findings in patients with spontaneous subarachnoid hemorrhage: when is digital subtraction angiography still needed? AJNR 2010; 31:696-705.

13. Kershenovich A, Rappaport ZH, Maimon S. Brain computed tomography angiographic scans as the sole diagnostic examination for excluding aneurysms in patients with perimesencephalic subarachnoid hemorrhage. Neurosurgery 2006; 59:798-801.

14. American college of radiology Appropriateness criteria: Cerebrovascular Disease 2016;2: $21-2$.

15. Prestigiacomo CJ, Sabit A, He W, Jethwa P, Gandhi C, Russin J: Three dimensional CT angiography versus digital subtraction angiography in the detection of intracranial aneurysms in subarachnoid hemorrhage. J Neurointerv Surg 2010; 2:385-9.

16. Kelliny M, Maeder P, Binaghi S, Levivier M, Regli L, Meuli R. Cerebral aneurysm exclusion by $\mathrm{CT}$ angiography based subarachnoid hemorrhage pattern: a retrospective study. BMC Neurol 2011; 11:8-22. 
17. Velthuis BK, Rinkel GJE, Ramos LMP, Witkamp TD, van Leeuwen MS. perimesencephalic Hemorrhage: exclusion of vertebrobasilar aneurysms with CT angiography. Stroke 1999; 30:1103-9.

18. Ruigrok YM, Rinkel GJE, Buskens E, Velthuis BK, van Gijn J. Perimesencephalic hemorrhage and CT angiography: a decision analysis. Stroke 2000; 31:2976-83.

19. Menke J, Larsen J, Kallenberg K: Diagnosing cerebral aneurysms by computed tomographic angiography: meta-analysis. Ann Neurol 2011;69:646-54.

20. Jayaraman MV , Mayo-Smith WW , Tung GA , et al . Detection of intracranial aneurysms: multi-detector row CT angiography compared compared with DSA . Radiology $2004 ; 230$ ( 2 ):510 - 518 .

21. Struffert T, Doelken M, Adamek E. Flat-detector computed tomography with intravenous contrast material application in experimental aneurysms: comparison with multislice CT and conventional angiography. Acta Radiol 2010 ; 51 ( 4 ): 431 - 437.

22. Donmez H, Serifov E, Kahriman G, Mavili E, Durak AC , Menkü A . Comparison of 16row multislice $\mathrm{CT}$ angiography with conventional angiography for detection and evaluationnof intracranial aneurysms . Eur J Radiol 2011 ; 80 ( 2 ): 455 - 461.

23. Yoon DY, Lim KJ , Choi CS , Cho BM, Oh SM , Chang SK . Detection and characterization of intracranial aneurysms with 16-channel multidetector row CT angiography: a prospective comparison of volume-rendered images and digital subtraction angiography . AJNR Am J Neuroradiol 2007 ; 28 ( 1 ): 60 - 67.

24.Westerlaan HE, van Dijk JM, der Weide MC J, de Groot JC, Groen RJ, Mooij JJ, Oudkerk M: Intracranial aneurysms in patients with subarachnoid hemorrhage: CT angiography as a primary examination tool for diagnosis - systematic review and meta-analysis. Radiology 2011; 258:134-45.

25. Xing W, Chen W, Sheng J, Peng Y, Lu J, Wu X, Tian J: Sixty-four-row multislice computed tomographic angiography in the diagnosis and characterization of intracranial aneurysms comparison with 3D rotational angiography. World Neurosurg 2011; 76:105-13.

26. Byyny RL, Mower WR, Shum N, Gabayan GZ, Fang S, Baraff LJ: Sensitivity of noncontrast cranial computed tomography for the emergency department diagnosis of subarachnoid hemorrhage. Ann Emerg Med 2008; 51:697-3.

27. Hayashida E, Sasao A, Hirai T, Hamasaki K, Nishi T, Utsunomiya D, Oda S, Iryo Y, Urata J, Yamashita Y: Can sufficient preoperative information of intracranial aneurysms be obtained by using 320-row detector CT angiography alone? Jpn J Radiol 2013; 31:600-7. 
Research article | SLR 